\title{
Revolucion antiesclavista y mediterraineidad ilustrada en Carpentier
}

Maribel Parra Domínguez ${ }^{1}$

\section{Resumo}

En este trabajo analizo el imaginario revolucionario antiesclavista de la obra literaria del escritor Alejo Carpentier dentro de la influencia que ejerció la ilustración como movimiento de liberación de los esclavos del Caribe. Para ello me centro en la conexión que el escritor cubano establece entre el sincretismo cultural de las prácticas rituales afrocaribeñas, su idea de mediterraneidad conectada a dichas prácticas y el pensamiento ilustrado de corte masón. Partiendo de esta base, propongo que esta episteme moderna conforma la estética de lo real maravilloso como modelo fundacional para la articulación de un nuevo vínculo cultural vía el Mediterráneo entre América y Europa.

Palavras-chave: Alejo Carpentier; esclavitud; ilustración; masonería; real maravilloso

\section{Abstract}

In this article I analyze the revolutionary antislavery imaginary present in the literary work by Alejo Carpentier within the Enlightenment's impact

${ }^{1}$ Professora do Centro Universitário Internacional da Universidade Pablo de Olavide ( Sevilha). Doutora em Literatura Espanhola e Máster em Literatura e Cultura Hispanoamericana. 
on the slave liberation movement in the Caribbean. To this end, I focus on the connection that the Cuban writer establishes among the cultural syncretism of Afro-Caribbean ritual practices, his idea of Mediterraneanity connected to those practices, and the mason-type Enlightenment thinking. Taking the above as a starting point, I propose that this modern episteme conforms the real maravilloso's aesthetics as a foundational model for the articulation of a new cultural link between America and Europe via the Mediterranean Sea.

Keywords: Alejo Carpentier; Enlightenment; masonry; real maravilloso; slavery

La revolución antiesclavista del Caribe vinculada al ideal independentista es un aspecto crucial en la estética de lo real maravilloso de Alejo Carpentier. Partiendo del concepto de episteme moderna que Foucault propone en Las palabras y las cosas, en este trabajo voy situar este imaginario estético revolucionario dentro de la expansión que el pensamiento masón adquirió con el movimiento antiesclavista caribeño durante elperíodo de la Revolución Francesa. Paraello, me voyaenfocaren el vínculo que el escritor cubano establece entre el ideal masón y las prácticas rituales afrocaribeñas en tres de sus obras: El siglo de las luces (1959), El reino de este mundo (1948) y Ecue-Yamba-O (1927). En primer lugar, analizaré el impacto que las logias y los ritos africanos ejercen sobre la conciencia de los personajes para pasar a la ruptura que finalmente experimentan entre el proyecto político revolucionario y la ética ilustrada. En mi análisis voya proponerque Carpentier sitúa la experiencia de lo maravilloso en la brecha que se produjo entre el pensamiento masón de base científica alquimista y la racionalidad jacobina- aniquiladora de cualquier tendencia mística o sagrada que apelara a lo irracional. Después, voy a interpretar esta ruptura con el cambio de episteme científica que Foucault sitúa en el paso del siglo XVIII al XIX, con la consiguiente repercusión que dicho cambio 
produjo en el campo de la metafísica. De esta forma, me interesa mostrar cómo en la estética de loreal maravilloso el sentido de las prácticas rituales afrocaribeñas puede insertarse dentro del debate que Foucault abre sobre la posibilidad de retomar el concepto de ilustración kantiana como punto de partida para la constitución de esa "actitud límite" que el filósofo francés identifica con la experiencia de lo sagrado. Esta actitud límite, que el escritor cubano construye a través de la etnología y la masonería, la voy a vincular a una idea de mediterraneidad ilustrada que sirve de enlace entre América y la cultura española identificada con el legado de Al-Andalus. Partiendo de esta base, planteo que esta episteme moderna conforma la estética de lo real maravilloso como modelo fundacional para la articulación de un nuevo vínculo cultural vía el Mediterráneo entre América y Europa. Por consiguiente, de manera paradójica, la ruptura que el imaginario antiesclavista de Carpentier establece con respecto al legado de la conquista posibilita una nueva vía de contacto cultural con España, en concreto, con la cultura mediterránea "orientalista" (africana y semítica) que acabó siendo expulsada del territorio peninsular como consecuencia de la realpolitik de la "Reconquista". Finalmente, planteo una reflexión sobre el concepto de mediterraneidad que Carpentier propone a través del ideal masón en respuesta al paradigma orientalista que Edward W. Said ha identificado con la hegemonía cultural del colonialismo europeo de los siglos XVIII y XIX y con su articulación racional a través de un corpus académico ilustrado.

En Las palabras y las cosas, Foucault utiliza el término "episteme" para analizar el modo de conocer moderno estableciendo que el siglo XVII "señala la desaparición de las viejas creencias supersticiosas y mágicas y, por fin, la entrada de la naturaleza en el orden científico". ${ }^{2} \mathrm{~A}$ partir de ese momento, la semejanza (modo de conocer medieval en el que las palabras tienen la misma realidad que aquello que significan) se

\footnotetext{
${ }^{2}$ Michael Foucault, Las palabras y las cosas. Trad. Elsa Cecilia Frost, Siglo XXI, Madrid, 1999, p. 61.
} 
sustituyó por la representación, donde el objeto empezó a representarse a partir de fórmulas y axiomas científicos. Con esta transformación estamos ante el concepto de leyes universales y ante la conformación de un sujeto trascendental, a priori. Estamos, en definitiva ante la entrada del racionalismo. Este principio de racionalidad científica sentó las bases de lo que posteriormente se conocería como Ilustración o Siglo de las Luces. Sobre él se articularon las transformaciones políticas y económicas que la nueva clase burguesa empezó a poner en marcha en su lucha contra los valores del Antiguo Régimen. Analizando las prácticas discursivas y científicas de este período, Foucault llega a la conclusión de que la idea del hombre no debe entenderse como parte de una tradición reflexiva sobre la naturaleza humana sino que surge entre 1775 y 1825 , etapa en la que el ser humano logra constituirse en sujeto y objeto del saber al mismo tiempo.

En este período, y como elemento fundacional de la modernidad, se produjo la expansión de la masonería como difusora de los ideales de lailustración. En Elmito de la Revolución Masónica, Eduardo R. Callaey sitúa el paso de la masonería operativa a la moderna masonería simbólica en 1717 en una taberna londinense. Allí se reunían los albañiles que habían participado en la construcción de antiguos palacios o en la reconstrucción de alguna catedral. En estas reuniones discutían sobre las técnicas de construcción, el conocimiento secreto de las tradiciones y los ritos del gremio, el sentido de los símbolos, etc. Lo peculiar es que ciertos "intelectuales" de la época (filósofos, burgueses y nobles) empezaron a incluirse en dichas reuniones tabernarias. Parece que las discusiones eran bastante acaloradas, llegándose a decir que los caballeros perdían sus modales aristocráticos poniéndose a la altura de una clase artesanal que, pese a su baja alcurnia, se constituía en heredera directa de un legado arquitectónico y esotérico alque los intelectuales querían tener acceso. En estas reuniones tabernarias, cuyas discusiones giraban en torno a nociones científicas, espirituales y alquímicas, hay dos aspectos que considero fundamentales para entender el rol que la masonería va a desempeñar 
en la difusión de los ideales de La Revolución Francesa: la especulación científica como parte del conocimiento filosófico y el ejercicio de la razón como base "democrática" para lalibertad de expresión y elestablecimiento de la idea de igualdad social.

La novela de Carpentier El siglo de las luces está completamente impregnada por el impacto que la masonería ejerció en el movimiento antiesclavistadelCaribe durante elperíodo dela Revolución Francesa. Los personajes, los hermanos Sofía y Carlos y su primo Esteban, son criollos cubanos de clase social alta. Viven en La Habana y se acaban de quedar huérfanos cuando en el puerto atraca The Arrow, una nave procedente de Port-au-Prince. En ella llega Victor Hugues, un negociante marsellés que jugará un papel militar relevante en los acontecimientos revolucionarios antiesclavistas que se producen en las islas caribeñas bajo el signo de la ilustración. La dimensión histórica se va narrando a través de la relación personal que Víctor mantiene con los personajes, especialmente con Sofía. En términos simbólicos, puede decirse que la ciencia entra en la casa de los cubanos con la llegada del marsellés ya que lo primero que Víctor Hugues pone en funcionamiento es un Gabinete de Física que los muchachos acaban de comprar. Hugues también los pone en contacto con Ogé, un médico mulato masón, distinguido, filántropo y educado en París, que cura a Esteban de sus dolencias asmáticas. Cuando Sofía reacciona de forma racista ante la presencia del "médico negro", empieza la instrucción por parte de Víctor al responderle con la máxima ilustrada: "Todos los hombres nacieron iguales" ${ }^{3}$ La práctica médica de Ogé, que Sofía califica de "brujería" y "curso de nigromancia", ${ }^{4}$ se fundamenta en una mezcla de ciencia y de creencias esotéricas sobre el efecto que las plantas ejercen en los seres humanos.

Esteban, impactado por su milagrosa mejoría, se va sintiendo fascinado por ese mundo masónico tan vinculado a los principios de

\footnotetext{
${ }^{3}$ Alejo Carpentier, El siglo de las luces, Seix Barral, S.A., Barcelona, 2001, p. 44.

${ }^{4}$ El siglo de las luces, p. 45.
} 
la razón ilustrada. Sofía y Carlos igualmente se sienten atraídos por ese universo de ideas que brota de las discusiones y debates que Víctor y Ogé mantienen sobre las libertades fundamentales del hombre, la religión y la ciencia:

$<<$ La Revolución está en marcha y nadie podrá detenerla $\gg$, dijo Ogé... Revolución, pensaba Esteban...

$<<$ Para empezar- decía Ogé- un reciente decreto autoriza al hombre de mi color... a desempeñar allá cualquier cargo público. ${ }^{5}$ La medida es de una importancia enorme. E-nor-me. $>$... : $<<\underline{\text { Hemos }}$ rebasado las épocas religiosas; entramos ahora en la época de la ciencia $>>$. <<La estratificación del mundo en clases carece de sentido. $>>\ldots<\mathrm{La}$ humanidad está dividida en dos clases: Los opresores y los oprimidos... Los términos de libertad, felicidad, igualdad, dignidad humana, regresaban continuamente en aquella atropellada discusión... ${ }^{6}$

Estas discusiones acaloradas que tanto impresionan a Sofía, a Carlos y a Esteban parecen evocar aquellas primeras reuniones que los masones mantenían en las tabernas. La nave The Arrow, en la que terminan reuniéndose, también se describe en la novela como si de una logia se tratara:

Esta nave tenía algo mágico con su capitán $<<$ filantrópico >>, perteneciente al mundo secreto de Víctor y Ogé- el de Isis y Osiris, Jackes de Molay y Federico de Prusia-, que conservaba su mandil, adornado con la Acacia, el Templo-de-Siete-Peldaños, las dos Columnas, el Sol y la Luna, en una vitrina junto a sus instrumentos de navegación. Por las noches, bajo el toldillo de popa, Ogé se daba a hablar

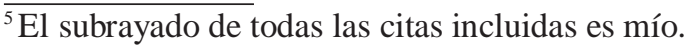

${ }^{6}$ Elsiglodelas luces, p. 66. 
de los portentos del magnetismo, de la quiebra de la psicología tradicional, o bien de las órdenes secretas que florecían en todas partes, bajo los nombres Hermanos del Asia, Caballeros del Águila Negra, Electos Cohen, Filaletas, Iluminados de Aviñón, Hermanos de la Luz Verdadera, Filadelfos, Caballeros Rosacruces y Caballeros del Templo, persiguiendo un ideal de igualdad y armonía, a la par que laboraban por el perfeccionamiento del Individuo, destinado a ascender, con el auxilio de la Razón y de las Luces, hacia las esferas donde el ser humano veríase por siempre librado de temores y dedudas... ${ }^{7}$

Los personajes cubanos se familiarizan con pensadores como Kant, Voltaire, Rousseau, Schiller, Chateaubriand, Fichte y acaban siendo iniciados endiferentes logias. Esteban se vaaFranciay allí se hacemiembro de la logia de los Extranjeros Reunidos:

Un día memorable fue iniciado en la Logia de los Extranjeros Reunidos, penetrando en el vasto mundo fraternal y laborante que Víctor sólo le hubiera reveladoaretazos. Paraélhabían encendidoel Templo, resplandeciente y arcano, donde al fulgor de las espadas, le tocara andar, trémuloy deslumbrado, hacia las Columnas Jachim y Boaz, el Delta y el Tetragrama, el Sello de Salomón, y la Estrella del número de Oro. ${ }^{8}$

La iniciación de Esteban le permite a Carpentier proporcionar información sobre las asociaciones, símbolos y emblemas que forman parte de la tradición masónica: los Caballeros Kadosh, los Caballeros de la Rosacruz, los Caballeros de la Serpiente de Bronce, Los Caballeros del Arca Real, los Príncipes del Tabernáculo, los Príncipes del Líbano, los Príncipes de Jerusalén, el Gran Maestre Arquitecto, el Sublime Príncipe del Real $\overline{{ }^{7} \text { El siglo de las luces, p. } 73 .}$

${ }^{8}$ El siglo de las luces, p.92. 
Secreto, los misterios del Grial, la transformación de la Piedra Bruta en Piedra Cúbica, la Resurrección del Sol en la Acacia, las bodas alquímicas de Christian Rosencreutz y el Secreto de los Templarios. Además de iniciarse formalmente en una logia parisina, Esteban también se pone en contacto con el Club de Jacobinos y con las peñas de los masones españoles que trabajan para llevar la Revolución a la Península. Concretamente presta sus servicios como traductor de textos y colabora para introducir en España el movimiento ilustrado. Cuando vuelve a La Habana, Esteban descubre que sus primos también son miembros de La Logia Andrógina, un centro masón fundado por Carlos con la finalidad de incluir a mujeres ilustradas. A esta logia igualmente pertenenece Jorge, un comerciante irlandés que llegará a convertirse en esposo de Sofía.

Elreino de estemundo estáconstruida con los mismosacontecimientos históricos de El siglo de las luces pero la narración se establece desde el punto de vista del esclavo negro haitiano. La novela gira en torno a la rebelión antiesclavista que lidera el brujo Mackandal, un mandinga cimarrón que utiliza el conocimiento científico de las plantas en su lucha contra la esclavitud (concretamente para envenenar a los blancos). Es curioso cómo en las novelas de Carpentier el conocimiento de la botánica se usa con una doble finalidad: paracurar y para matar. Sin embargo, ambas prácticas se muestran al servicio del concepto de libertad y fraternidad difundidos por la ilustración. En general, puede decirse que los ritos que los esclavos realizan en contra de la esclavitud se presentan como prácticas liberadoras del individuo en el sentido más ilustrado del término:

Nuestros dioses nos piden venganza... iRompan la imagen del Dios de los blancos, que tiene sed de nuestras lágrimas; escuchemos en nosotros mismos la llamada de la libertad!. 9

${ }_{9}^{9}$ Alejo Carpentier, El reino de este mundo, Seix Barral, Barcelona, 1986, p. 54. 
Esta llamada a la rebelión se describe como parte de un rito africano "Vaudoux" que la sacerdotisa del Radá realiza con un "machete ritual" invocando al dios Ogún. Los rebeldes deciden redactar una proclama y piensan en un "sacerdote volteriano que daba muestras de inequívocas simpatías por los negros desde que había tomado conocimiento de la Declaración de los Derechos del Hombre", ${ }^{10}$ lo que viene a mostrar el vínculo que Carpentier establece entre la praxis ritual del Caribe y el marco ideológico de la ilustración. Precisamente, el personaje Monsieur Lenormand de Mezy, un monárquico francés que compra al protagonista Ti Noel para su plantación del Cabo francés, manifiesta su gran inquietud por las nuevas ideas que se discuten en la Asamblea Constituyente de Francia ya que, "integrada por una chusma liberaloide y enciclopedista", "había acordado que se concedieran derechos políticos a los negros"." Junto a la historia de Mackandal, El reino de este mundo presenta la rebelión antiesclavista de Bouckman y el mundo imperial de negros que el cocinero Henri Christophe edifica en torno a un monumental palacio rodeado de jardines al más puro estilo francés. Estos acontecimientos históricos que, como dije anteriormente, aparecen en El siglo de las luces, se representan ahora desde la cosmovisión mandinga que Mackandal le trasmite a Ti Noel.

La narración de Ecue-Yamba-Oestádentro del período histórico que comienza después de la Independencia cubana. No obstante, uno de los personajes, el viejo Lui, cuenta la historia de su padre Juan Mandinga dentro del impacto ideológico que la masonería ejerció en laépoca de la esclavitud:

...El viejo Juan Mandinga... supo caerle en gracia al amo. El amo de aquel ingenio no era como tantos otros. Se le había afiliado a la masonería. Leía unos libros franceses que hablaban de la igualdad entre los

${ }^{10}$ El reino de este mundo, p. 57.

${ }^{11}$ El reino de este mundo, p. 57. Lenormand de Mezy es un esclavista del que se dice que abandonóla masonería para volver a abrazar la doctrina católica. Carpentier representa a este personaje totalmente desubicado dentro del pensamiento masón. 
hombres... Uno de los primeros en alzarse contra los tercios españoles. ${ }^{12}$

Menegildo, el negro protagonista de la novela, se hace eco de estos derechos de igualdad cuando piensa: “¿Qué tenían los negros? ¿No eran hombres como los demás?". ${ }^{13}$ Pero lo más destacable de Ecue-Yamba-O es el hecho de que la masonería se presente vinculada a la cultura de los ñáñigos o Abakúa, unas sociedades fraternales secretas cuyos miembros se consideran los masones de África. Estas sociedades secretas sólo existen en Cuba, en la zona de La Habana y en Matanzas. Sus ritos fueron traídos por los carabalíes, unos pueblos del antiguo Calabar de Nigeria del sur y Camerún, y su cosmovisión sagrada se basa en una leyenda que narra el hallazgo de un pez sagrado por parte de la princesa Sikán. El mundo espiritual de Menegildo es el de la santería, transmitida por su madre Salomé y el brujo Beruá -médico de la familia por ser gran conocedor de "la mitología revelada" y del "lenguaje de los árboles y el alma farmacéutica de las yerbas". ${ }^{14}$ Pero, como parte de su trayectoria espiritual, Menegildo acaba siendo iniciado en la masonería africana.

Parece evidente la conexión que Carpentier establece entre el sincretismo religioso tan característico de las prácticas rituales afrocaribeñas

\footnotetext{
${ }^{12}$ Alejo Carpentier, Ecue-Yamba-O, Seix Barral, Barcelona, 1986, p. 94.

${ }^{13}$ Ecue-Yamba-O,p. 64. En el textotambién resulta significativala presencia deCristalina Valdés, una médium espiritista que hacía uso de un retrato de Allán Kardek con un triángulo masónico, un Cristo italiano, un San Lázaro cubano, una esfinge de Maceo y una máscara de Víctor Hugo porque consideraba que "todos los hombres grandes eran transmisores". De entre los hombres que la médium cubana cataloga de "transmisores", meinteresa destacar la figura de Allán Kardek. Kardek es un intelectual francés que se dedicó al estudio de las ciencias y la filosofía. Uno de sus objetivos era desentrañar las consecuencias filosóficas del espiritismo partiendo de la idea de que los fenómenos sobrenaturales estaban sometidos a leyes naturales hasta ese momento desconocidas por la ciencia. De esta forma, en consonancia con la episteme moderna a la que pertenecía, Kardek contraponía el concepto de superstición al de "orden de la naturaleza". Junto a la base científica, racional, que proponía para los fenómenos de orden espiritista y ritual, el pensador francés igualmente apelaba a la tríada ilustrada: igualdad, libertad y fraternidad.

${ }^{14}$ Ecue-Yamba-O, p. 60.
} 
y el sincretismo cultural de la masonería como medio de exploración y conocimiento de la naturaleza del ser humano. Es bien sabido que la masoneríaes una organización filantrópica que hace uso de diferentes mitos y tradiciones mediterráneas, tanto místicas como filosóficas: los misteriosde Isis y Osiris del antiguo Egipto, la alquimia griega y árabe, los mitos clásicos, la Kábala, el pensamiento pitagórico y epicúreo, los escritos de los teósofos y espiritistas, etc. De hecho, en El siglo de las luces, la primera reacción que Sofía muestra con respecto a la masonería es de gran "desconcierto ante un movimiento de ideasque revestíatantas formas diversas y contradictorias". ${ }^{15}$ Se puede decir que en el seno de la modernidad europea tenemos unas logias de muy diferentestendencias, que, estando al servicio de la ciencia y larazón ilustrada, incorporantradiciones rituales y míticas del Antiguo Egipto y de la cultura mediterránea en general sin que tales tradiciones sagradas representen un problema para el ejercicio de dicha racionalidad. Por el contrario, estas tradiciones de origen alquímico, gnóstico y pagano son para los masones un importante material de conocimiento sobre la naturaleza, la cultura y la psicología humanas. En este sentido, es revelador que Carpentier presente el Mar Caribe africano como heredero directo del Mar Mediterráneo al que España se cierra con la llegada de la Reconquista (y de la Inquisición):

Y ya que el Venerable Beda y San Ambrosio y Duns Escoto situaban el Paraíso en el Oriente, y a ese Oriente creían haber llegado los hombres de Europa navegando con el Sol y no contra el Sol, se afirmaba la deslumbradora evidencia de que la Isla Española, llamada de SantoDomingo era Tarsis, era Caethia, era Ofir y era Ofar y era Cipango -todas islas o tierras mentadas por los antiguos que mal se hubiesen ubicado hasta ahora en un universo cerrado por España, como lo había sido la Península entera por obra de sus reconquistadores. ${ }^{16}$

\footnotetext{
${ }^{15}$ El siglo de las luces, p. 67.

${ }^{16}$ El siglo de las luces, p. 219.
} 
Porsupuesto, este vínculo entre la cultura delMediterráneo yel sincretismo religioso incluye a los dos Caribes (el español y el francés). Así se percibe enEl reinode este mundo cuando el haitiano TiNoel se quedaasombrado al identificar a sus dioses africanos en la Catedral de Santiago:

El negro hallaba en las iglesias españolas un calor de vodú que nunca había hallado en los templos sansulspicianos del Cabo. Los oros del barroco, las cabelleras humanas de los Cristos, el misterio de los confesionarios recargados de molduras, el can de los dominicos, los dragones aplastados por santos pies, $\underline{\mathrm{el}}$ cerdo de San Antón, el color quebrado de San Benito, las Vírgenes negras... tenían un poder de seducción, por presencias, símbolos, atributos y signos, parecidos al que se desprendía de los altares de los houmforts consagradosaDamballah, elDios Serpiente. Además, Santiago es Ogún Fai, el mariscal de las tormentas a cuyos conjuros se habían alzado los hombres de Bouckman. Por ello, Ti Noel, a modo de oración le recitaba a menudo un viejo canto oído a Mackandal:

\section{$\underline{\text { Santiago, soy hijo de la guerra }}$}

Santiago,

¿no ves que soy hijo de la guerra? ${ }^{17}$

Estáclaro que no es el legado oficial de laconquista el que establece el vínculo entre ambos mares. Por el contrario, son las prácticas rituales afrocaribeñas de los esclavos, los parias de América, las que conectan el mar Mediterráneo con el mar caribeño. Este planteamiento estético está dentro del conocimiento etnológico que el propio Carpentier describe cuando descubre el vínculo cultural que existe entre los mitos clásicos y los ritos americanos:

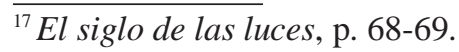


Y un día recuerdo que pregunté a un etnólogo que se encontraba haciendo trabajos de investigación en aquella región: $<<_{i}$ Tienen estos indios, los piaroas, porejemplo, alguna protohistoria? > Es decir, ¿tienen nociones de alguna historia heroica, como la tuvieron los antiguos pueblos de la Hélade, por ejemplo? Me dijo: <<Sí, cómo no...>> y me contó varias leyendas...Y me contó una que me dejó asombrado: la de una guerra habida entre dos tribus causada por el rapto de una hermosa mujer. Me dije: <<Bueno, pero esto, en el fondo, responde a los mitos universales. Esto es la guerra de Troya $>$. Y a partir de ese momento empecé a verlo todo en función americana: la historia, los mitos, las viejas culturas que nos habían $\underline{\text { llegado de Europa... Empiezo a traer Europa hacia }}$ acá y a verla de aquí hacia allá. ${ }^{18}$

Partiendo de esta conexión entre mito griego y experiencia ritual americana, Carpentier construye un concepto de mediterraneidad mestiza, que, vinculada a los mitos de la antigüedad clásica, se sitúa abiertamente dentro del parámetro de una modernidad ilustrada. Y es esta línea antropológica que va de lo local a lo universal la que le permite al escritor cubano considerar que el surrealismo es una simple "artimaña literaria". ${ }^{19}$

Ahora bien, Carpentier también muestra en sus novelas la confrontación que se produjo entre un ideal ilustrado masón de tradición iluminista, alquimista y sagrado, y el racionalismo de corte jacobino que acabó marcando la trayectoria política de la Revolución Francesa. En su estudio sobre la masonería y la Revolución Francesa, Callaey explica cómo muchos de los masones de tendencia espiritual fueron denunciados por otros masones que se decantaron por el racionalismo pragmático que

\footnotetext{
${ }^{18}$ Alejo Carpentier, Tientos y Diferencias. Y otros ensayos, Janés Editores, Barcelona, 1994, p.99.

${ }^{19}$ Tientos y Diferencias. Y otros ensayos, p. 75.
} 
antepuso el interés político a los derechos fundamentales del ser humano. Callaey utiliza el término "masonería quebrada" ${ }^{20}$ para refererise a lo que yo entiendo como una "fractura" en el seno de la propia modernidad. En El siglo de las luces Sofía percibe los signos de una divergencia que, al final de la novela, se transformará en una contradicción irreconciliable:

Ogé no era ateo a la manera de Víctor, para quien los sacerdotes cristianos eran $<<$ meros arlequines vestidos de negro que movían marionetas $>$, en tanto el Gran Arquitecto podía aceptarse como un símbolo pasajero en espera de que la ciencia acabara de despejar los enigmas de lacreación. ${ }^{21}$

Frente al racionalismo laicista de Víctor, el mulato Ogé sigue la doctrina masónica iluminista de Martínez de Pascually, ${ }^{22}$ de ahí que haga referencia a la Biblia, la kábala y el platonismo. Esta divergencia se va recrudeciendo hasta el punto de que Víctor, para el que "Todos esos magos e inspirados no son sino una tanda de emmerdeurs", ${ }^{23}$ le llega a ordenar a Esteban que abandone la logia:

Nada de masonerías. Si quieres estar con nosotros, no vuelvas a poner los pies en una Logia. Demasiado tiempo hemos perdido ya con esas pendejadas... La masonería es contrarrevolucionaria. Es cuestión que nose discute. No hay más moral que la moral jacobina. Y,tomando un Catecismo del Aprendiz que estaba sobre

${ }^{20}$ Eduardo R. Callaey, El mito de la revolución masónica, Ediciones Nowtilus S.L., Madrid, 2007, p. 157.

${ }^{21}$ El siglo de las luces, p. 73-74.

${ }^{22}$ Joachim Martínez de Pascually fue el fundador de la orden de los Caballeros Masones Élus Cohen del Universo que introdujo la doctrina cabalística en la masonería. Hacia 1772, en pleno auge e influencia de la francmasonería en el Caribe, llegó a Puerto Príncipe donde fundó templos y logias. Aunque Carpentier dice en la novela que era portugués, Callaey asegura que era un español de origen valenciano. En cualquier caso, es un personaje bastante enigmático del que no se sabe demasiado.

${ }^{23}$ El siglo de las luces, p. 97. 
la mesa, lo rompió por el canto de la encuadernación, arrojándolo al cesto de papeles. ${ }^{24}$

Hugues llega a encarnar esa "masonería quebrada" que surge como consecuencia de la imposición unilateral del racionalismo político jacobino. Esteban, que ha sido testigo directo de este horror jacobino, le confiesa a Sofía que la Revolución ha fracasado y que Víctor, el que fuera maestro y mentor de todos ellos, se ha convertido en un "monstruo". Esta palabra se hace especialmente significativa por las referencias a los aguafuertes de Goya que Carpentier incluye como citas introductorias de la novela a partir del capítulo segundo. La imagen simbólica de uno de sus caprichos, El sueño de la razón produce monstruos, parece evidente. ${ }^{25}$ Sofía llegará a entender el alcance de la advertencia de Estebancuando descubra que Hugues está apoyando el restablecimiento de la esclavitud en las colonias:

El hombre que había vencido a Inglaterra en la Guadalupe... había mostrado una energía tenaz, casi sobrehumana, para abolir la esclavitud ocho años antes, y ahora mostraba la misma energía en restablecerla. ${ }^{26}$ Víctor Hugues, citando a Bonaparte, intenta convencer a Sofía de su deber como político: "Hemos terminado la novela de la Revolución; nos toca ahora empezar su Historia y considerar tan sólo lo que resulta posible en la aplicación de sus principios" y concluye diciéndole que "la esclavitud es una necesidad política". 27

El protagonista de Ecue-Yamba-O muestracon la mismacontundencia de Esteban el escepticismo que siente ante la política cuando se pregunta: “¿De qué había servido la Guerra de Independencia, que tanto mentaban los oradores políticos, si continuamente era uno desalojado por estos hijos

\footnotetext{
${ }^{24}$ El siglo de las luces, p. 94.

${ }^{25}$ Sobre la dimensión pictórica de El siglo de las luces volveré más adelante.

${ }^{26}$ El siglo de las luces, p. 287.

${ }^{27}$ El siglo de las luces, p. 286.
} 
de la gran perra...?". ${ }^{28}$ Pero, frente al desamparo social que esta política le proporciona, Menegildo se siente confortado con las creencias sagradas que tiene en la fraternidad del ñáñigo, su masonería africana. En El reino de este mundo, Ti Noel sufre un profundo desengaño con respecto a la revolución cuando es sometido a la esclavitud en ese mundo prodigioso de negros que ha construido Henri Christophe. Pero las enseñanzas sagradas que le transmite Mackandal lo conducen a un conocimiento interno que puede entenderse como la máxima ética de la novela:

Y, comprendía, ahora, que el hombre nunca sabe para quién padece y espera. Padece y espera y trabaja para gentes que nunca conocerá, y que a su vez padecerán y esperarán y trabajarán para otros que tampoco serán felices, pues el hombre ansía siempre una felicidad situada más allá de la porción que le es otorgada. Pero la grandeza del hombre está precisamente en querer mejorar loque es. En imponerse Tareas. En el Reino de los Cielos no hay grandeza que conquistar, puesto que allá todo es jeraraquía establecida, incógnita despejada, existir sintérmino, imposibilidad de sacrificio, reposo y deleite. Por eso, en medio de su miseria, capaz de amar en medio de las plagas, el hombre sólo puede hallar su grandeza, su máxima medida en el Reino de este Mundo. ${ }^{29}$

Esta reflexión forma parte de la tesis que Fichte utiliza para explicar, precisamente, el objetivo de la masonería:

El único fin de la existencia humana sobre la tierra no es el cielo ni el infierno, sino sólo la humanidad que llevamos sobre nuestros hombros y su máximo desarrollo posible. Otra cosa no conocemos, y lo que llamamos divino, diabólico o bestial, no es sino humano.

\footnotetext{
${ }^{28}$ Ecue-Yamba-O, p. 67.

${ }^{29}$ El reino de este mundo, p. 150.
} 
Cuanto se halla por encima o por debajo de la humanidad está fuera del círculo de sus pensamientos, de sus esfuerzos y sus obras. ${ }^{30}$

En esta fractura que se produce entre la dimensión espiritual y la praxis política dentro del pensamiento masón considero que está la clave para entender el concepto de mediterraneidad ilustrada que Carpentier construye a través de "lo real maravilloso". Es en este espacio de desencuentro donde los personajes, traspasando los límites de la razón que conduce al pragmatismo político colonizador, experimentan una revelación interna que los lleva a percibir la realidad de una forma "transfigurada":

No hay más Tierra Prometida que la que el hombre puede encontrar en sí mismo. Y, al decir esto, pensaba Esteban en Ogé, que tan a menudo citaba una frase de su maestro Martínez de Pascually: El ser humano sólo podrá ser iluminado por el desarrollo de las facultades divinas dormidas enélpor el predominiode lamateria... ${ }^{31}$

Esteban también sufre una alteración en la conciencia, cuando a su vuelta de Francia, visualiza en Sofía a la Sophia Sapientia de la tradición alquímicaun arquetipo femenino que encarna la sabiduría de Dios $:^{32}$

$<<.$. Entonces se produjo el deslumbramiento... Fue ella, la primera mujer conocida, madre estrechada por ti en vez de la que nunca llegaste a conocer. Es ella la hembra que te reveló las esplendorosas ternuras de la hembra en el insomnio velado, la compasión de tus padecimientos y la apaciguadora caricia dada en el alba. Es ella la hermana que conoció las sucesivas formas de tu cuerpo como sólo

\footnotetext{
${ }^{30}$ Johann GottliebFichte, Filosofía de la masonería. Cartasa Constant.Trad.Faustino Oncina Coves y Manuel Ramos Valera, Ediciones ISTMO S.L., Madrid, 2007, p. 38.

${ }^{31}$ El siglo de las luces, p. 234.

${ }^{32}$ Marie von Franz, Alquimia, Trad. Marta I. Guastavino, Grupo Editorial Océano, Barcelona 1991.
} 
una amante inimaginable, crecida contigo, hubiera podido conocerlas. ${ }^{33}$

La alquimia es una de las principales tradiciones mediterráneas que la masonería incorpora en sus inicios, ${ }^{34}$ quizás porque, como apunta Carl Jung, con la tradición alquímica estamos ante "la aurora de la época científica", donde la experiencia del orden místico o espiritual se presenta vinculada a un espíritu científico que consigue poner la naturaleza al servicio del hombre:

Lo que anhelaban los alquimistas no era la separación de la naturaleza sino la unión con la misma. Su leit motiv fue desde Demócrito: la naturaleza alegra la naturaleza, la naturaleza vence la naturaleza, y la naturaleza domina la naturaleza. Este principio es de origen pagano y es una confesión del antiguo sentimiento de la naturaleza. La naturaleza no sólo contiene un proceso de transformación, es la transformación misma. No anhela el aislamiento, $\underline{\text { sino la coniunctio, la fiesta nupcial, la muerte y la }}$ resurrección. $^{35}$

La Sofía de El Siglo de las Luces experimenta esta coniunctio alquímica o fiesta nupcial en la relación sexual que mantiene con Víctor Hugues:

Colmada de carne, volvía hacía las gentes, los libros, las cosas, con la mente quieta, admirada de cuán inteligente era el amor físico. Había oído decir que ciertas sectas orientales consideraban el contento de la carne como un paso necesario para la elevación hacia

$\overline{{ }^{33} \text { El siglo de las luces, p. } 241 .}$

${ }^{34}$ Callaey ofrece información sobre la relación entre la alquimia y la masonería. Concretamente se centra en la relación que Hesse-Cassel y Federico el Grande tenían con sabios alquimistas como Saint Germain.

${ }^{35}$ Carl G. Jung. Paracélsica, Trad. Eduardo García Belsunce, Nilo-Mex, Ciudad de México 1983, p. 104. 
la Trascendencia, y llegaba a creerlo al observar que en ella se iba afianzando una insospechada capacidad de Entendimiento... Releyendo ciertos textos clásicos... descubría la esencia original de los mitos. ${ }^{36}$

La revelación interna de los mitos clásicos que Sofía adquiere a través de la carne (su naturaleza orgánica) es la que le proporcionará el fundamento ético que le permita abandonar a Hugues cuando se dé cuenta del proyecto político que este está llevando acabo:

< La Revolución ha trastornado a más de uno»>, dijo Víctor. $\ll$ Es esto, acaso, lo magnífico que hizo la Revolución: trastornar a más de uno- dijo Sofía. Ahora sé lo que debe rechazarse y lo que debe aceptarse. $>>37$

Esto es lo que en su libro sobre la masonería Fichte define como "formación para la libertad ética" ${ }^{38}$ Junto a lo dicho, me interesa destacar que la concepción ritual de Ecue-Yambao-O parece tener el mismo sentido pagano que el concepto alquímico de muerte y resurrección del que habla Jung. La narración entera se articula como si de un ciclo sagrado se tratase: empieza con el nacimiento del protagonista, sigue con su iniciación en la masonería africana, continúa con su muerte tras la realización de un rito que lo transporta al ansiado estado de trance, para culminar con un renacimiento simbólico en la figura de su hijo Menegildo ante el sabio Beruá y la imagen de SanLázaro-Babayú-Ayé.

El proceso de muerte y resurrección alquímica que Jung vincula a la tradición pagana tiene una fuerte analogía con la función simbólica de Isis y Osiris, mitos mediterráneos muy utilizados por la masonería. Precisamente, Marie von France afirma que Isis es el punto de partida de

\footnotetext{
$\overline{{ }^{36} \text { El siglo de las luces, p. } 280 .}$

${ }^{37}$ El siglo de las luces, p. 298.

${ }^{38}$ Filosofía de la masonería. Cartas a Constant, p. 68.
} 
la alquimia. Jung también estudia a Paracelso, un médico del siglo XVI, como figura intelectual que introduce la kábala dentro de la especulación alquimista. El mundo de El siglo de las luces se abre con una cita delZohar ("Las palabras no caen en el vacío") como parte del legado mediterráneo masón del que se nutre toda la novela. La cosmovisión sagrada de los ritos afrocaribeños que Carpentier nos muestra a través de su estética de lo real maravilloso comparte la misma concepción pagana de la naturaleza en la que se sustenta la tradición alquímica:

....empezaría el Áfricanuevamente; ;...alaadoraciónde los Dioses Primeros, anteriores a los Dioses recientes del Cristianismo... para alcanzar los tiempos en que la Creación fuese regida por la Venus Fecunda, ,... adorada en cavernas profundas... ${ }^{39}$

los hombres de color capaces de hacer perdurar la gran tradición de una ciencia legada durante siglos,... de iniciadores a iniciados. ${ }^{40}$

La ruptura que he presentado dentro del seno de la masonería entre la racionalidad política que acaba liderando el proyecto de la Revolución Francesa y la tradición espiritual que vincula la alquimia con los mitos mediterráneos y las prácticas rituales afrocaribeñas, la voy a analizar dentro del cambio que, según Foucault, se produjo en el sistema de positividades al pasar del siglo XVIII al siglo XIX. Según el filósofo francés, si el conocimiento científico que se impuso en el siglo XVII estableció la ruptura con el pensamiento que se apoyaba en la similitud como forma de acceder a la verdad, el siglo XIX marcará una nuevaruptura con esa racionalidad dieciochesca separando los contenidos empíricos del

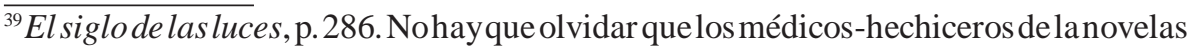
se comportan como alquimistas en la utilización farmacéutica que hacen de las plantas, de lo que puede deducirse que el concepto de la naturaleza que tienen estos personajes encaja dentro del mismo orden científico de Allén Kardek, el filósofo ilustrado que la médium de Ecue-Yamba-O utiliza como "transmisor".

${ }^{40}$ Ecue-Yamba-O, p. 59.
} 
sistema de representación en el que se basaba la premisa kantiana de la "duplicación de lo empírico en lo trascendental". Foucault explica cómo las consecuencias de esta ruptura, en la que el cogito se desvincula de lo impensado, se hicieron sentir en el ámbito de la metafísica:

...Desde que los contenidos empíricos se separaron de la representación e implicaron en sí mismos el principio de su existencia, la metafísica del infinito se hizo inútil; la finitud no dejaba de referirse a sí misma (de la positividad de los contenidos a las limitaciones del conocimiento, y de la positividad limitada de éste al saber limitado de los contenidos). Así pues, todo el campo del saber occidental se invirtió. Allí donde en otro tiempo había una correlación entre una metafísica de la representación y de lo infinito y un análisis de los seres vivos, de los deseos del hombre y de las palabras de su lengua, vemos constituirse una analítica de la finitud y de la existencia humana y, en oposición a ella (pero en una oposición correlativa), una tentación perpetua de constituir una metafísica de la vida, del trabajo y del lenguaje. ${ }^{41}$

En términos foucaultianos, con la cancelación de la metafísica del infinito se abandonó el espacio de la representación, lo que trajo consigo la "muerte de la metafísica" y el nacimiento del hombre como objeto de un conocimiento científico que se desvinculaba de lo trascendental.

Es muy conocido el análisis que Foucault hace de Las Meninas de Velázquez como paradigma kantiano de la representación de la realidad y de su duplicación como forma de acceder al conocimiento científico de la naturaleza. Desde mi punto de vista, en El siglo de las luces Carpentier recurre a la pintura -a la representación- como forma de acceso a ese conocimiento ilustrado que queda desbancado con el nacimiento de la nueva metafísica decimonónica circunscrita exclusivamente a lo finito.

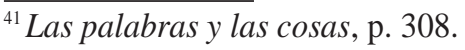


Aunque las pinturas objetivamente visibles en la novela son Explosión en la Catedral y los aguafuertes de Goya, el cuadro que considero más significativo es el que viene a la mente del/a lector/a al final de la narración. Se trata de Losfusilamientos del 3 de mayo y puede deducirse de la participación de Sofía y Esteban en las revueltas que el pueblo de Madrid llevó a cabo en contra de los franceses:

... en todo Madrid... Noche de lóbrega matanza, de ejecuciones en masa, de exterminio, en el Manzanares y en Moncloa. Las descargas de fusilería... en el ritmo tremebundo de quienes apuntan y disparan... Aquella noche de un comienzo de mayo...Las calles estaban $\underline{\text { llenas de cadáveres... Ni Sofía ni Esteban regresaron }}$ nunca. $^{42}$

La imagen iluminada que aparece en el centro del cuadro de Goya puede entenderse como parte de esa "visión exaltada" de la realidad que los personajes experimentan con el conocimiento ilustrado que adquieren a través de la tradición masónica. Cuando Carpentier ofrece su definición de "lo real maravilloso", deja muy claro que hay que entender este concepto como una exaltación que se produce en la conciencia del ser humano y que lo lleva a alterar de forma milagrosa el sentido de la realidad en la que vive:

Lomaravillosocomienzaaserlodemanerainequívoca cuando surge de una inesperada alteración de la realidad (el milagro), de una revelación privilegiada de la realidad, de una iluminación inhabitual... percibidas con particular intensidad en virtud de una exaltación del espíritu que lo conduce a un modo de "estado límite". ${ }^{43}$

$\overline{{ }^{42} \text { El siglo de las luces, p. } 311 .}$

${ }^{43}$ Véase el prólogo de El reino de este mundo, Ediap, México, 1949. 
Este "estado límite" es el que puede identificarse con el sistema de representación que Carpentier propone entre los protagonistas de su novela y el cuadro de Goya.

En Ecue-Yamba-O Menegildo llega a ese estado de exaltación con eléxtasis que alcanza con la música y los bailes rituales. EnEl reino de este mundo Ti Noel igualmente llega al "estado límite" con el conocimiento de la naturaleza que le ha trasmitido Mackandal. En consecuencia, en la estética de lo real maravilloso la alteración inesperada de la realidad que sufren los personajes se fundamenta en el ejercicio de unas prácticas sagradas que, dentro del marco de una idea de mediterraneidad semítica y africana conectada a la masonería ilustrada, parte de una racionalidad que apunta a la transgresión de sus propios límites. Nietzsche ya había constatado la valentía de Kant al mostrar los límites de la razón y su victoria sobre el optimismo de la lógica:

Si ese optimismo apoyado en las aeternae veritates ha creído en la posibilidad de conocer y escrutar todos los enigmas del mundo y ha tratado el espacio, el tiempo y la causalidad como leyes incondicionales de validez universalísima, Kant reveló que propiamente esas leyes servían tan sólo para elevar la meta de la apariencia, obra de Maya, a realidad única y suprema y para ponerla en el lugar de la esencia más íntima y verdadera de las cosas, y para hacer así imposible el verdadero conocimiento de esa esencia. ${ }^{44}$

Según Nietzsche, la plena conciencia del límite de la razón es lo que, precisamente, dará lugar a una cultura trágico-griega, mediterránea, que él mismo define como la combinación de lo dionisíaco (la música que nos lleva a la pérdida de los límites) y lo apolíneo (la imagen plástica que nos reconduce a la fragilidad de dichos límites). A modo de ejemplo, el

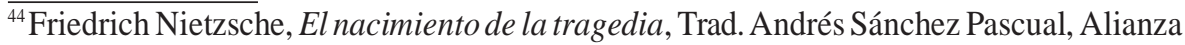
Editorial, Madrid, 1995, p. 148.
} 
filósofo alemán también recurrió a un cuadro de Rafael, La transfiguración, para explicar el concepto de representación que podía establecerse con la transgresión del límite kantiano; transgresión donde la naturaleza, puesta al servicio de la voluntad, transfigura al ser humano para situarlo en el espacio de los dioses paganos. Es en esta conciencia del límite donde Nietzsche sitúa la idea del superhombre que Jung rastrea en el espíritu de la alquimia:

En la alquimia medieval se preparaba la gran intromisión en el orden divino, que siempre ha osado el hombre... A partir del espíritu de la alquimia, Goethe creó la figura del "superhombre" Fausto y a partir de este superhombre, elZaratustra de Nietzsche ha declarado la muerte de Dios y ha anunciado la voluntad de dar a luz, por propia plenitud de dominio, al superhombre. ${ }^{45}$

El marco de la masonería que permea la estética de lo real maravilloso parece apostar por la experiencia de lo sagrado como medio paraestableceruna nuevarelación entre el cogito y lo impensado a través de mitos encarnados en manifestaciones antropológicas que se expresan como vivencias liberadoras. Y es en esta nueva relación donde se fundamenta un concepto de mediterraneidad ilustrada que, estrechamenterelacionada con un imaginario simbólico antiesclavista, parece desbancar tanto el modelo político-cultural de la conquista de corte oficialmente católico, como el colonialismo de la modernidad racional que se implanta con las invasiones napoleónicas. En su libro Orientalismo, Edward W.Said ilustra muybien el marco de legitimación intelectual de este colonialismo moderno:

En el siglo XVIII y principios del XIX, empezó el Orientalismo moderno- un resurgir de lo Oriental-una conciencia de Oriente desde China al Mediterráneo.... ${ }^{46}$

\footnotetext{
${ }^{45}$ Paracelsia, p. 58.
}

${ }^{46}$ Edward W. Said, Orientalismo, Trad. María Luisa Fuentes, Random House Mondadori, 
Occidente... asumió que Oriente- y todo lo que en él había... necesitaba ser estudiado, rectificado por él. Oriente se examinaba enmarcado en un aula, un tribunal, una prisión o un manual ilustrado... ${ }^{47}$

El Orientalismo estuvo sometido al imperialismo, al positivismo, a la utopía, al historicismo, al darwinismo, al racismo, al psicoanálisis, al marxismo, a las teorías de Spengler, etc... tuvo sus paradigmas de investigación, sus propias sociedades culturales y su propia organización interna. ${ }^{48}$

En términos amplios, el Orientalismo estableció una dicotomía entre el racionalismo moderado, maduro y legítimo de Occidente y la irracionalidad, el infantilismo y la barbarie medieval de las culturas no europeas. Es innegable que la cultura latinoamericana en general, por su hibridez, ha sido una de las más sometidas al paradigma colonizador de esta decimonónica dicotomía. Y, dentro del ámbito geográfico europeo, España (especialmente Andalucía) ha estado siempre estigmatizada por su conexión privilegiada con África y las culturas de Al-Andalus. En este sentido, quiero destacar el movimiento ilustrado andalucista de los años 20 y 30 que, en abierta confrontación con el casticismo del 98, planteaba la apertura de Andalucía hacia África, el Mediterráneo y Latinoamérica. Las semejanzas que encontramos con el planteamiento de Alejo Carpentier pueden pensarse a través de la ilustración masona a la que se suscribe dicho movimiento andaluz. Como en la estética de lo real maravilloso, el modelo de ilustración andaluza igualmente apelaba a la recuperación de un paganismo griego, mediterráneo, a través de manifestaciones antropológicas rituales que, como el flamenco, se vinculaban al legado morisco, interpretándose como fuerzas de liberación que rompían con el pensamiento filosófico de la modernidad. Y, como los personajes de las

\footnotetext{
S. A, Barcelona, 2008, p. 71

${ }^{47}$ Orientalismo, p. 69

${ }^{48}$ Orientalismo, p. 72
} 
novelas de Carpentier, los andalucistas también plantearon la ruptura con este pensamiento moderno por su sometimiento servil "al principio de las naciones" (a políticas nacionalistas con intereses económicos coloniales), frente "al principio de las culturas" que defendían para la construcción de un ideal ético ilustrado que desmontara el estigma orientalista al que se veía sometido el Mediterráneo semítico y africano.

El desencuentro que la estética de lo real maravilloso plantea entre elámbito de la ética y la política se puede relacionar con la la reflexión que hace Carpentier cuando destaca que el concepto de independencia que Voltaire, Diderot, Rosseau, etc, redactaron en la Enciclopedia a mediados del siglo XVIII, tenía un valor exclusivamente filosófico y no político. Tanto es así que la Independencia de los Estados Unidos no trajo consigo la emancipación de los esclavos, acontecimiento histórico que no llegó a producirse hasta la Guerra de Secesión. Por el contrario, fue el esclavo del Caribe el que realmente dotó a América de una idea de libertad política que se remonta a las guerras anticoloniales del siglo XVI. ${ }^{49}$ Este dato es de máxima relevancia paracomprender la fuerte carga de revolución ilustrada que Carpentier percibe en la praxis antiesclavista de los ritos afrocaribeños como fundamento para la construcción de una ética de liberación que se desmarca de la filosofía europea por su continuo sometimiento a la política. En este sentido, el escritor cubano nos muestra el logos filosófico occidental en su máxima debilidad para liderar el proyecto ético de la ilustración en tanto que carece de voluntad firme para llevar a la práctica los principios de justicia, igualdad y libertad que tanto abandera desde al ámbito intelectual. En su libro, Said reflexiona sobre la posibilidad de pensar en una alternativa contemporánea al orientalismo "preguntándose cómo se pueden estudiar otras culturas y pueblos desde una perspectiva libertaria, y no represiva o manipulativa" ${ }^{50}$ Creo que la mediterraneidad ilustrada que Alejo Carpentier articula a través de la masonería posibilita

\footnotetext{
${ }^{49}$ Tientos y Diferencias. Y otros ensayos, p. 206-207.

${ }^{50}$ Orientalismo, p. 49
} 
la idea de una modernidad construida desde el otro lado de la dicotomía. Como mencioné anteriormente, la música ritual (lo dionisíaco) y la pintura (lo apolíneo) son elementos que el escritor utiliza para conformar la racionalidad delsiglo de las luces a partir de la exaltación delespíritu al que llegan los personajes transgrediendo los límites de dicha racionalidad. ${ }^{51}$ Así como Carpentier utiliza el "estado límite" para definir lo real maravilloso, Foucault define el "ethos filosó fico" que identifica con esta transgresión como una "actitud límite" donde "la crítica de lo que somos es a la vez un análisis histórico de los límites que nos han establecido y un examen de su franqueamiento posible". ${ }^{52}$ En esta línea, la recuperación del sistema de representación que el escritor caribeño propone en su estética de lo real maravilloso apunta al restablecimiento de una metafísica de lo infinito que, asumiendo la imposibilidad de alcanzar verdades trascendentales, se constituye en esa abertura que Foucault define como la "ontología crítica de nosotros mismos" que nos puede permitir "salir del chantaje intelectual y político de estar a favor o en contra de la Aufklärung". ${ }^{53}$ La salida de este chantaje se conforma a través de un concepto de mediterraneidad que, frente al legado político colonialista legitimado por la racionalidad europea, se posiciona estableciendo puentes con las culturas excluidas a ambos lados del Atlántico. En palabras de Carpentier, de este "Mediterráneo Caribe surge un José Martí". ${ }^{54} \mathrm{La}$ afiliación masónica de Martí, iniciado en la Logia Armonía de Madrid en 1871, es un antecedente que le da mayor sentido al vínculo que he planteado entre el Mediterráneo y el Caribe a través del marco de una

\footnotetext{
${ }^{51}$ Said destaca cómo en Las bacantes, "quizás el drama más asiático de todos los dramas atenienses, a Dionisos se le relaciona de manera explícita con sus orígenes asiáticos y con los excesos extrañamente amenazadores de los misterios orientales". Orientalismo, p.89.

${ }^{52}$ Las palabras y las cosas, p. 351. Vésase también "Prefacio a la transgresión" del mismo autor en De lenguaje y literatura. Trad. Isidro Herrera Baquero, Ediciones Paidós Ibérica, Barcelona 1996, p. 123-142.

${ }^{53}$ Michael Foucault “¿Qué es la ilustración? En Estética, ética y hermenéutica, Trad. Ángel Gabilondo, Ediciones Paidós Ibérica, Barcelona, 1999, p. 335-352.

${ }^{54}$ Tientos y Diferencias. Y otros ensayos, p. 73.
} 
masonería ilustrada latinoamericana que puede estudiarse en relación al ideal cultural andalucista, de corte igualmente masón. ${ }^{55}$

\section{Fuentes}

CARPENTIER, Alejo, El reino de este mundo, México, Ediap, 1949.

CARPENTIER, Alejo, Ecue-Yamba-O, Barcelona, Seix Barral, 1986.

CARPENTIER, Alejo, El reino de este mundo, Barcelona, Seix Barral, 1986.

CARPENTIER, Alejo,Elsiglo de lasluces,Barcelona: Seix Barral, S.A. 2001.

CARPENTIER, Alejo, Tientosy Diferencias. Yotros ensayos, JanésEditores, Barcelona, 1994.

\section{Bibliografía}

FICHTE CALLAEY,Eduardo R, El mito de la revolución masónica, Madrid, Ediciones Nowtilus S.L., 2007.

FICHTE, Johann Gottlieb, Filosofía de la masonería. Cartas a Constant, Trad. Faustino Oncina Coves y Manuel Ramos Valera, Madrid, Ediciones ISTMO S.L., 2007.

FOUCAULT, Michael, Las palabras y las cosas. Trad. Elsa Cecilia Frost. Madrid: Siglo XXI, 1999.

FOUCAULT, Michael, "Prefacio a la transgresión" En De lenguaje y literatura. Trad. Isidro Herrera Baquero, Barcelona, Ediciones Paidós Ibérica, 1996, p. 123-142.

\footnotetext{
${ }^{55}$ En El Orientalismo como discurso bidireccional entre Andalucía y América (artículo en preparación) analizo el impacto cultural del orientalismo europeo a través de ambos movimientos ilustrados (el andaluz y el latinoamericano).
} 
FOUCAULT, Michael, “¿Qué es la ilustración? En Estética, ética y hermenéutica, Trad. Ángel Gabilondo, Barcelona, Ediciones Paidós Ibérica, 1999, p. 335-352.

JUNG, Carl G. Paracélsica,Trad. Eduardo García Belsunce. Ciudad de México, Nilo-Mex, 1983.

NIETZSCHE, Friedrich, El nacimiento de la tragedia, Trad. Andrés Sánchez Pascual, Madrid, Alianza Editorial, 1995.

SAID, Edward W, Orientalismo, Trad. María Luisa Fuentes, Random House Mondadori, S. A, Barcelona, 2008.

VON FRANZ, Marie, Alquimia, Trad. Marta I. Guastavino. Barcelona, Grupo Editorial Océano, 1991. 